\title{
How to Avoid Communication Conflicts Between Chinese and English Speakers
}

\author{
WANG Jian-ying \\ Qingdao University of Science \& Technology, Qingdao, China
}

\begin{abstract}
Chinese core values are very different from those of people in English speaking countries, and this makes communication styles very different. When Chinese communicate with people from other cultures, cultural awareness sometimes helps make the communication easier and more effective. When people are in a bi-cultural or even multi-cultural situation, they need to be aware of the cultural differences. On the other hand, for various reasons, cultural barriers may arise. This can occur when the people concerned speak entirely different languages or hold entirely different values and communication styles. This essay examines how native Chinese speakers communicate with or without words and how the effectiveness of what people say can be helped or hindered by the various messages their language and bodies send. Only when communicators are aware of their own communicative styles and those of others can they avoid communication conflicts. Observing and respecting other people's communication styles during the adjustment of one's own communication behaviors should be an on-going task in the intercultural communication.
\end{abstract}

Keywords: communication conflicts, perspectives, cultural awareness, cultural barriers, effectiveness

\section{Introduction}

Successful intercultural communicative behavior includes the ability to react appropriately in a social interaction situation, to predict how a communicative strategy is likely to apply in a specific communicative situation, to decide on and evaluate the form of communicative style, to manifest an attitude for making one's own communicative behavior acceptable, and to demonstrate culturally acceptable methods of analyzing and identifying different communicative purposes. This enables significant mutual understandings between the information sender and the receiver. The following strategies are designed to help Chinese English users to communicate with native English speakers.

\section{Starting a Conversation With Appropriate Small Talk}

Small talk is light conversation on unimportant or non-serious subjects. Some people think that small talk is meaningless and a waste of time, but it is quite useful for the purpose of initiating communication. It helps to start a conversation, but how do people start small talk with foreigners? Finding an appropriate topic is half the battle. Some topics work well but others, such as age, money, or people's appearance are inappropriate.

WANG Jian-ying, associate professor, School of Foreign Language Studies, Qingdao University of Science \& Technology. 
In a social gathering where a lot of guests are strangers to one another, small talk can be very useful to make people feel at ease. Safe topics are the weather, the TV programs that one saw last night or little compliments on what people are wearing. If talking about the weather, people normally add some kind of personal evaluation. For example, they might say “Isn't all this rain dreadful?” This shows the speaker's feelings about the weather and invites a response from the listener. Unlike Chinese people, English speakers are ready and willing to talk about political topics. They have freedom to express their own opinions, for example, if they criticize Chinese leaders, they are not criticizing the country. They criticize their own political leaders too, sometimes very vehemently.

\section{Conducting a Conversation}

In daily communication, people often use different techniques to conduct a conversation. They need to know how to show attention or surprise, how to agree or disagree, how to break into a conversation, how to change the subject, and how to bring other people into a conversation. The expressions "Really?", "No kidding!", "Imagine that!" indicate your participation in the topic of conversation. "By the way..." and "Come to think of it..." are expressions one uses when he/she tries to change the topic. When people conduct the conversation carefully, misunderstandings are minimized between listeners and speakers.

\section{Developing a Cross-Cultural Perspective in Using English}

In everyday life, people have to deal with many kinds of situations that require them to obtain information from others. It is important to go about getting this information in the right way. In most cases, people can ask directly but be polite in doing so. Most English people are very polite when they ask a stranger about something. They put a question by saying "Excuse me, could you...?" "I wonder if you could tell me..." "Could you tell me...?" Between friends, it is quite all right to say simply "Tell me..." or use the question words "what", "where", "when", "how", etc. to get the information they need. However, Chinese people should avoid trying to get information that is considered private. For example, reading a foreigner's personal papers without asking for permission is absolutely unacceptable. So too is asking money-related questions such as "how much did you pay for your car?"

Among Chinese, questions such as "Have you had your breakfast?" or "Where are you going?" are often used to greet a person or to initiate a conversation. To native speakers of English, however, the question about breakfast would suggest an invitation and therefore may cause misunderstanding. Similarly, the question "Where are you going?" when expressed in English, is normally a request for information and not just a greeting. Such questions should be avoided.

In the West, directly asking adults, especially women, their age is generally regarded as impolite. "How much do you earn?" is also a rude question as income is considered as an extremely personal and private affair. Asking native speakers of English directly how much they paid for something is also regarded as an invasion of their privacy. If you really want to get information about the cost of something, you should use indirect ways. For example, instead of "How much did it cost?" one can say "Was it very expensive?" This gives the respondent a choice of reply. They may say "Yes," they may say "Not really" or, if they are comfortable doing so, they may state the price.

Chinese have to make their spoken English not only grammatically correct but also socially acceptable 
when they are communicating in English. In other words, they should develop a cross-cultural perspective in using English.

\section{Making an Impression to Conduct a Cross-Cultural Conversation}

There are similarities in the Chinese culture and the cultures in English speaking countries in the way of getting other people's attention. One's impression management skill helps others make judgments as to whether they would be interested in him/her. First impressions often contribute to the success of communication and one's social influence. But how can people strengthen chances of making a good impression when conducting a cross-cultural conversation? Here are some strategies:

\section{Preliminary Researching of Listener's Interests}

Anticipating the listener's interests demonstrates to the listener that you care about the topic you are discussing and gives both parties the opportunity for further conversation. Keeping your responses related to your life experience encourages the listener to tell you their interests. For example, when you ask what one can do in such terrible weather, the listener might reply "I just stay at home and read a book." This prompts another question: "What sort of book do you like to read?" Thus you gain an opportunity to learn about his/her interests. You can take advantage of this opportunity of learning more about the listener to carry on the conversation smoothly.

\section{Maintaining Eye Contact}

Many Chinese tend to avoid looking at the person they are talking to. To foreigners this gives the impression that they are nervous, lacking in confidence, or perhaps not speaking the truth. Failing to maintain eye contact is a Chinese habit that needs to be resisted when speaking to English speakers.

\section{Keeping Miscellaneous Communication Considerations in Mind}

The traditional Chinese concept holds that it is the duty of the young or a junior to do something for the elder or the superior. Underlings may use such expressions as "Are you tired?" "That was a hard job", or "Take a break, please!" to show gratitude and concern. But when we talk to an English speaker our relative ages or social positions do not have this impact on what we say

\section{Handling Questions Gracefully}

Many Chinese regard questions as an attack. When they are asked many questions about their work, for example, they think the questioner is checking up on them and if too many questions are asked they may take offense. But for English speakers, asking questions is a way of showing interest; otherwise they would not bother. If they do not know the answer to a specific question, they can answer a different but related question or just honestly say "I am sorry, I don't know". This lets the conversation move forward.

\section{Being a Good Listener}

Chinese should let an English speaker with whom they are conversing tell them information about him/her or the topic they are talking about. By asking questions they show they think he/she is important to others. They may find that they can sail through a conversation by simply asking insightful questions. Unfortunately many Chinese people are simply waiting to interrupt an English speaker to show how much they are interested in the topic. This interrupting is considered rude and can be very annoying to English speakers. 
People's chosen method of communication can totally influence the success or failure of their attempt to gain attention. For example, some Chinese managers depend heavily on giving instructions in writing, believing this has more impact and effect. Foreign managers, on the other hand, generally prefer face to face communication with their Chinese colleagues unless it is a more official communication.

\section{Not Sending Mixed Messages in Cross-Cultural Conversation}

Mixed messages make people feel unsafe when Chinese communicate with people from an English speaking cultural background; they need to make their words, gestures, facial expressions, and tone match. For example, Chinese have a different means of expressing appreciation. People laugh to show appreciation whereas their laughter may be perceived as deprecatory. For example, Chinese may laugh when foreigners speak Chinese to show they appreciate their effort. This may mislead the foreigner, making them feel they are being mocked for their poor Chinese language. People need to be aware of such cultural differences to avoid intercultural confusion.

\section{Conclusion}

Culture has a great influence on perceptions. Even though people may be consciously attempting to avoid problems, they are unavoidably making ethnic judgments as they are communicating. Therefore, when people are learning to communicate, they should learn not only spoken language but also various cultural perceptions. Communicators use both verbal and nonverbal codes to communicate and listeners expect to receive both kinds of messages during communication. If an information sender uses these codes inappropriately, the receiver may consider the person either a poor communicator or a rude person. Accurate communicative styles contribute to successful communication with people from different cultural backgrounds.

\section{References}

Bennet, M. J. (1998). Basic concepts of intercultural communication: Selected readings. Yarmouth, ME: Intercultural Press. Efron, Z. (1941). Gesture and environment. New York: Academic Press.

Hall, E. (1948). The hidden culture. New York: Anchor Books Double Day Press.

Kramsch, C. (1991). Language and culture. Oxford: Oxford University Press.

Lusting, M. W., Koester, J., \& Smith, S. L. (1998). Intercultural competence. London: LANG MAN.

Morain, G. G. (1986). Kinesics and cross-cultural understanding. London: London Cambridge University Press.

Robertson, I. (1981). Sociology (2nd ed.). N.Y.: Worth Publishers.

Samovar, L. (1981). Understanding international communication. Wadsworth: Wadsworth Publishing Company.

Segall, M. H., \& Dasen, P. R. (1992). Cross-cultural psychology: Research and applications. Cambridge: Cambridge University Press. 